\title{
Semicontinuous Bioreactor Production of Recombinant Butyrylcholinesterase in Transgenic Rice Cell Suspension Cultures
}

\author{
Jasmine M. Corbin ${ }^{1}$, Bryce I. Hashimoto ${ }^{1}$, Kalimuthu Karuppanan ${ }^{1}$, Zachary R. Kyser ${ }^{1}$, \\ Liying $W u^{2}$, Brian A. Roberts ${ }^{3}$, Amy R. Noe $^{3}$, Raymond L. Rodriguez ${ }^{4}$, \\ Karen A. McDonald ${ }^{1}$ and Somen Nandi ${ }^{4 *}$ \\ ${ }^{1}$ Chemical Engineering and Materials Science, University of California, Davis, Davis, CA, USA, ${ }^{2}$ Arcadia Biosciences, Davis, \\ CA, USA, ${ }^{3}$ Leidos, Inc., Frederick, MD, USA, ${ }^{4}$ Global HealthShare ${ }^{\circledR}$, Molecular and Cellular Biology, University of California, \\ Davis, Davis, CA, USA
}

\section{OPEN ACCESS}

Edited by: Kazuhito Fujiyama,

Osaka Univeristy, Japan

Reviewed by:

Guotian Li,

University of California, Davis, USA

Nozomu Koizumi,

Osaka Prefecutre University, Japan

Jochen Büchs,

RWTH Aachen University, Germany

*Correspondence:

Somen Nand

snandi@ucdavis.edu

Specialty section:

This article was submitted to

Plant Biotechnology,

a section of the journal

Frontiers in Plant Science

Received: 12 December 2015

Accepted: 17 March 2016

Published: 31 March 2016

Citation:

Corbin JM, Hashimoto BI,

Karuppanan K, Kyser ZR, Wu L, Roberts $B A$, Noe AR, Rodriguez RL,

McDonald KA and Nandi S (2016)

Semicontinuous Bioreactor

Production of Recombinant

Butyrylcholinesterase in Transgenic

Rice Cell Suspension Cultures.

Front. Plant Sci. 7:412.

doi: 10.3389/fpls.2016.00412
An active and tetrameric form of recombinant butyrylcholinesterase (BChE), a large and complex human enzyme, was produced via semicontinuous operation in a transgenic rice cell suspension culture. After transformation of rice callus and screening of transformants, the cultures were scaled up from culture flask to a lab scale bioreactor. The bioreactor was operated through two phases each of growth and expression. The cells were able to produce BChE during both expression phases, with a maximum yield of $1.6 \mathrm{mg}$ BChE/L of culture during the second expression phase. Cells successfully regrew during a 5-day growth phase. A combination of activity assays and Western blot analysis indicated production of an active and fully assembled tetramer of BChE.

Keywords: butyrylcholinesterase, rice amylase 3D, inducible promoter, plant cell culture, semicontinuous culture

\section{INTRODUCTION}

Butyrylcholinesterase (BChE, EC 3.1.1.8) is a native human serine hydrolase enzyme that has been shown to function as a bioscavenger against various organophosphorus nerve agents, with both prophylactic and therapeutic applications (Lenz et al., 2005). BChE is a complex tetrameric protein comprised of four identical $85 \mathrm{kDa}$ monomers, each with $9 \mathrm{~N}$-linked glycosylation sites (Lockridge, 2015). BChE can be purified from expired human blood plasma, but low yields and high costs (anticipated $>$ US $\$ 10,000$ per treatment dose) limit its use (DARPA, 2012). Therefore, there is a pressing need for a cost-effective platform for recombinant production of BChE.

Recombinant BChE has been successfully produced in several expression systems, including transgenic goats and mice (Huang et al., 2007), insect cells (Brazzolotto et al., 2012), transgenic plants (Geyer et al., 2010), transient expression in plants (Schneider et al., 2014a), and CHO cells (Ilyushin et al., 2013; Terekhov et al., 2015). However, a major limitation in the production of recombinant $\mathrm{BChE}$ is the need to produce tetrameric $\mathrm{BChE}$, which has a significantly longer circulatory half-life than the dimeric or monomeric forms (Duysen et al., 2002). Many of these systems show incomplete tetramerization of the molecule (Huang et al., 2007; Geyer et al., 2010; Brazzolotto et al., 2012; Schneider et al., 2014b). While there has been success with production of fully tetrameric $\mathrm{BChE}$ in $\mathrm{CHO}$ cells through coexpression of the enzyme with a proline-rich peptide (Terekhov et al., 2015), mammalian systems are susceptible to contamination with mammalian pathogens and require extensive regulatory clearances for human therapeutic use. Whole plant systems can avoid this problem, but also require specialized facilities to grow and harvest transgenic material or to transiently express foreign proteins. 
Plant cell suspension cultures, however, offer many advantages over alternative expression systems for the production of human therapeutics. These include (1) a simple, low cost, animal component-free, chemically-defined medium; (2) lack of susceptibility to contamination with mammalian pathogens; and (3) the ability to perform complex post-translational modifications such as glycosylation (Huang and McDonald, 2012). Unlike with whole plant systems, plant cell cultures can make use of already existing cell culture infrastructure. Thus, a plant cell suspension culture is well suited to address the difficulties associated with production of BChE.

In particular, the use of the rice alpha amylase 3D (RAmy3D) expression system in a rice cell suspension culture enables efficient, high-level expression of foreign proteins (Huang et al., 2001). The RAmy3D system contains an inducible promoter that is activated by sugar starvation and a signal peptide that tags the protein for secretion into the culture medium. This allows for a cyclical or semicontinuous operation of the culture in which the cells are subjected to multiple phases of growth and expression by alternating between a sugar-rich and sugar-free medium. In addition, use of an inducible expression system may alleviate some of the problems associated with reduced productivity over long culture times that has been observed for plant cell cultures that utilize constitutive expression systems (Raven et al., 2015). Semicontinuous operation can further reduce culture costs by eliminating the shut down and start up time between runs that would be necessary in a batch culture system. Although RAmy3D has been successfully used for the production of other recombinant proteins in rice cell culture (Huang et al., 2002; Trexler et al., 2005; Park et al., 2010), it has not been used to produce a molecule as large and complex as BChE.

To address the need for effective, scalable, and active BChE, we have designed and studied a transgenic rice cell suspension culture for the production of BChE using the RAmy3D expression system. This study demonstrates semicontinuous bioreactor production of an active form of $\mathrm{BChE}$, which with continued development, can provide a reliable system for production of this molecule as a therapeutic or prophylactic.

\section{MATERIALS AND METHODS}

\section{Expression Vector Design and Cloning}

The native human BChE (NCBI NM_000055) coding sequence without the native secretion signal peptide was modified for expression in rice and inserted into a vector (pUC57) containing the RAmy3D promoter, signal peptide, and terminator sequences using GenScript (GenScript, Piscataway, NJ). The native human BChE coding sequence was codon optimized for expression in rice and analyzed using Visual Gene Developer (http:// visualgenedeveloper.net). The sequence was modified without any changes in the amino acid sequence of the mature protein. The overall GC content of the DNA sequence was increased from 40.2 to $51.4 \%$, and the codon adaptation index was changed from 0.68 to 0.83 . The final construct was then cloned in a binary vector (pCAMBIA2300) and incorporated via heat shock into Agrobacterium tumefaciens strain EHA 105 for transformation.

\section{Transformation and Selection of Callus}

The transformation was performed as described in Huang et al. (2001) with minor modifications. Callus derived from seeds of Oryza sativa cv. Taipei 309 were co-cultivated with A. tumefaciens containing the described vector at $\mathrm{OD}_{600}=1.0$ for $20 \mathrm{~min}$. The callus was transferred to semi-solid medium and incubated in the dark at $25^{\circ} \mathrm{C}$ for 3 days before washing three times with a solution of $200 \mathrm{mg} / \mathrm{L}$ timentin and $250 \mathrm{mg} / \mathrm{L}$ cefotaxime. Finally, the callus was transferred to a sucrose $(\mathrm{S})$ rich semi-solid selection medium ("NB") that contains N6 macronutrients (Chih-Ching et al., 1975), B5 micronutrients and vitamins (Gamborg et al., 1968), $2 \mathrm{mg} / \mathrm{L}$ 2,4-dicholorophenoxyacetic acid (2,4-D), $250 \mathrm{mg} / \mathrm{L} \mathrm{L}$ proline, $250 \mathrm{mg} / \mathrm{L}$ L-glutamine, $300 \mathrm{mg} / \mathrm{L}$ casein hydrolysate, $30 \mathrm{~g} / \mathrm{L}$ sucrose, $1.8 \mathrm{~g} / \mathrm{L}$ gelzan, and $50 \mathrm{mg} / \mathrm{L}$ geneticin as the selection antibiotic, denoted as $\mathrm{NB}+\mathrm{S}$. Previous studies show that supplementation with proline and glutamine promotes callus induction (Pawar et al., 2015).

\section{Screening of Transformed Callus}

Transformed callus was subjected to eight rounds of screening at increasingly larger scales in selection media containing geneticin (as the selection antibiotic). The first round of screening evaluated 310 transformation events and was performed in a 96 well plate. Callus was transferred from semi-solid $\mathrm{NB}+\mathrm{S}$ to a well containing liquid $\mathrm{NB}+\mathrm{S}$ (same composition as described above) and stored in an Innova 4000 incubator/shaker (Eppendorf, Inc., Hauppauge, NY) at $60 \mathrm{rpm}$ and $27^{\circ} \mathrm{C}$ in the dark for 5 days. Induction was performed by sterilely pipetting off the spent $\mathrm{NB}+\mathrm{S}$ medium and replacing it with an equal volume of $\mathrm{NB}-\mathrm{S}$ medium, which has the same composition as $\mathrm{NB}+\mathrm{S}$ except that the sucrose $(\mathrm{S})$ is replaced with $8 \mathrm{~g} / \mathrm{L}$ mannitol. Samples of both the spent medium and biomass were collected and analyzed at $120 \mathrm{~h}$ after induction. After the fourth round of screening, the top 10 transformation events were used to establish shake flask cultures. Flasks with nominal volumes between $125 \mathrm{~mL}$ and $1 \mathrm{~L}$ were filled to $1 / 5$ full and maintained at $140 \mathrm{rpm}$ and $27^{\circ} \mathrm{C}$ in the dark in the same incubator/shaker. Flask screenings were performed in the same manner as well plate screenings. After the 8th round of screening, a single, top-performing cell line was selected based on cell physiology (healthy appearance, light color, friable aggregates) and BChE expression stability, and suspension cultures of this line were maintained through weekly sub-culturing with fresh liquid $\mathrm{NB}+\mathrm{S}$ medium.

\section{Bioreactor Operation}

Cultures were scaled up for operation in a $5 \mathrm{~L}$ bioreactor (BioFlo 3000, Eppendorf, Inc., Hauppauge, NY) equipped with a single pitched blade impeller. To obtain small and consistently sized aggregates, cultures were sieved at the time of inoculation by pressing the biomass through a $280 \mu \mathrm{m}$ pore size stainless steel mesh sieve (Sigma Aldrich, St. Louis, MO).

The bioreactor was operated under conditions similar to those described in Trexler et al. (2002) with slight modifications. The bioreactor was maintained at $27^{\circ} \mathrm{C}, 75 \mathrm{rpm}$ (agitation speed), and $40 \%$ (air saturation) dissolved oxygen (Mettler Toledo $\mathrm{O}_{2}$ sensor). The dissolved oxygen level in the culture was controlled by altering the concentration of oxygen, nitrogen, and air in the 
gas sparging stream, and the overall gas flow rate was maintained between 0.2 and $0.4 \mathrm{vvm}$. The oxygen uptake rate was determined by measuring the change in dissolved oxygen in the culture in the absence of aeration. The $\mathrm{pH}$ of the culture was monitored but not controlled. The cultures were grown under ambient light, and the conditions were identical for both growth and expression phases.

Induction of BChE expression in the bioreactor was performed using gravity sedimentation. After the biomass was allowed to settle, a peristaltic pump and sterile tube welder were used to remove the spent $\mathrm{NB}+\mathrm{S}$ medium and replace it with fresh $\mathrm{NB}-\mathrm{S}$ medium. For semicontinuous operation, another growth phase was initiated by following the same procedure described above, by removing the $\mathrm{NB}-\mathrm{S}$ medium and replacing with $\mathrm{NB}+\mathrm{S}$ medium.

\section{Biomass Measurements}

Four well-mixed $10 \mathrm{~mL}$ samples were taken every $24 \mathrm{~h}(48 \mathrm{~h}$ during the initial growth period) from the reactor under sterile conditions through the sampling port. One sample was set aside for protein extraction and quantification, and the remaining three were used to determine the fresh weight (FW) and dry weight (DW) of cells by washing them in $10 \mathrm{~mL}$ double distilled water (to remove residual sugars) on a pre-weighed $1.6 \mu \mathrm{m}$ Binder-Free Glass Microfiber filter (Whatman GF/A $4.7 \mathrm{~cm}$, GE Healthcare Life Sciences, Pittsburgh, PA). The combined filter and biomass was weighed immediately to obtain the FW, then dried in an oven at $65^{\circ} \mathrm{C}$ for $24 \mathrm{~h}$ and weighed again to obtain the DW.

\section{Sugar Analysis}

The concentrations of sucrose and glucose in the culture medium were measured using YSI 2900 Biochemistry Analyzer (Xylem, Inc., Rye Brook, NY). Cell-free medium from reactor sampling was passed through a $0.22 \mu \mathrm{m}$ syringe filter to remove any remaining cells and stored at $4^{\circ} \mathrm{C}$ until analysis. The YSI 2900 enzymatically measures sucrose and glucose concentrations in a given sample and can account for any interaction between the signals from each. Samples were measured at $2 \mathrm{X}$ and $4 \mathrm{X}$ dilutions with double distilled water to ensure concentrations of each sugar were within the accurate detection range of the instrument.

\section{Quantification of Active Intracellular BChE}

Concentration of active BChE was measured separately in the medium (by analyzing crude culture medium) and associated with the cell mass (by analyzing the crude cell extract). The cell extract was prepared by grinding the callus in a 1:1 ratio in cold homogenization buffer $(100 \mathrm{mM}$ sodium phosphate, $100 \mathrm{mM} \mathrm{NaCl}, \mathrm{pH}$ 7.4) using a Tissue Tearor (Biospec Products, Bartlesville, OK) operated at maximum speed for $30 \mathrm{~s}$. The homogenized sample was then centrifuged a $14,000 \mathrm{~g}$ for $10 \mathrm{~min}$, and the supernatant was saved in a new tube and stored at $4{ }^{\circ} \mathrm{C}$ until analysis.

Active BChE concentration in each sample was measured using a modified Ellman activity assay (Ellman et al., 1961). The assay monitors the hydrolysis of butyrylthiocholine in the presence of Ellman's reagent in $100 \mathrm{mM}$ sodium phosphate buffer, $\mathrm{pH}$ 7.4. This reaction was monitored using a spectrophotometer (SpectraMax 340PC, Molecular Devices, Sunnyvale, CA) to measure the absorbance at $405 \mathrm{~nm}$ over a period of $3 \mathrm{~min}$ at $25^{\circ} \mathrm{C}$. Samples were concentrated (with a $30 \mathrm{kDa}$ ultrafiltration membrane) or diluted to fall within the accurate detection range of $0.5-1.0 \mathrm{ng} \mathrm{BChE} / \mu \mathrm{L}$ sample. Once the concentration of BChE from a sample was determined, it was normalized to the mass of fresh weight biomass, volume of extraction buffer, or volume of total culture.

\section{Quantification of Total Soluble Protein}

The total soluble protein (TSP) in a sample was measured using a Bio-Rad Protein Assay kit (Bio-Rad, Hercules, CA), which is based on the method of Bradford (Bradford, 1976). The assay was performed per manufacturer's instructions. Each sample was analyzed in triplicate, including protein standards used to generate a standard curve.

\section{Gel Electrophoresis and Immunoblotting}

SDS-PAGE was performed using a $4-15 \%$ gradient gel, and native-PAGE using a $7.5 \%$ gel (Mini-PROTEAN precast gels, BioRad, Hercules, CA). Western blotting was performed using a 1:200 dilution of mouse anti-BChE IgG as the primary antibody and a 1:2000 dilution of goat anti-mouse IgG-HRP as the secondary antibody (Santa Cruz Biotechnology, Dallas, TX), and developed by incubation with 3,3',5,5'-tetramethylbenzidine (TMB) substrate. PEGylated recombinant human BChE derived from transgenic goats (PharmAthene, Inc, Annapolis, MD) and native equine serum BChE (Sigma Aldrich, St. Louis, MO) were used as controls.

\section{RESULTS}

\section{Transformation and Screening}

The rice-optimized $\mathrm{BChE}$ gene construct was cloned into the RAmy3D (Huang et al., 2001) expression system (Figure 1) and subsequently into A. tumefaciens for gene delivery by cocultivation. Stable integration of incoming recombinant DNA into cellular DNA is largely a random process, and accordingly, the sites of integration are dispersed throughout the genome. The ability to backcross and screen independent transgenic events can produce more stable arrangements and expression of the transgene in whole plants (Chih-Ching et al., 1975; Park et al., 2010). For transgenic cell lines, however, the process is more complex. Although primary calli can be selected for a particular antibiotic resistance and screen for the expression of a particular recombinant protein, genetic and epigenetic changes that occur during multiple cycles of cell differentiation and dedifferentiation can produce somaclonal variation in the calli (Gamborg et al., 1968). These somaclonal variants can exhibit a wide range of morphological and physiological phenotypes, including variations in the expression of the transgene.

To meet our goal for stable protein expression over many generations of microcalli propagation, extensive screening was performed to identify the lines that provide optimal protein production. Over 1000 transformants, from 310 independent transformation events were initially selected and grown on semi-solid selection medium. Of these, 105 events produced a 
detectable amount of $\mathrm{BChE}$, with varying levels of expression (data not shown). Figure 2 shows the combined amounts of active secreted and cell-associated BChE from the top 20 transformation events during the first screening. After 8 rounds of screening, one cell line (identified as line "9-2") was selected based on the expression stability and cell-line physiology for continued development and scale up, and was used for all remaining analyses described in this study.

\section{Cell Growth, Oxygen Uptake, Sugar Consumption, and BChE Expression Kinetics}

The semicontinuous bioreactor culture was operated for 31 days and underwent two cycles each of growth and expression. Figure 3A shows the growth of the biomass over the duration of the culture. The first growth phase (Growth 1) had an initial biomass concentration of $0.21 \pm 0.07 \mathrm{~g} \mathrm{DW} / \mathrm{L}$ of culture and lasted 16 days, while the second growth phase (Growth 2) had an initial biomass concentration of $2.37 \pm 0.06 \mathrm{~g}$ DW/L and lasted 5 days. Growth 1 exhibited a long lag phase of 4 days followed by a long exponential phase of 12 days prior to induction, while Growth 2 had a lag of $<1$ day and a 5 day exponential phase. This difference is likely due to the difference in the initial biomass concentration during each growth phase. During each expression phase, where $\mathrm{NB}+\mathrm{S}$ was removed and replaced with $\mathrm{NB}-\mathrm{S}$, the biomass concentration immediately dropped as some of the biomass was pumped out of the reactor along with the spent medium. However, at the beginning of expression, the biomass concentration increased as the cells received fresh medium components such as nutrients and amino acids. The biomass concentration soon leveled off and began to drop as the cells starved from sugar deprivation, until a new growth phase was initiated. Table 1 summarizes the cell growth kinetics for both growth phases. The maximum specific growth rate $\left(\mu_{\max }\right)$ increased from $0.15 \pm 0.01 \mathrm{day}^{-1}$ during Growth 1 to $0.22 \pm$ 0.01 day $^{-1}$ during Growth 2, which correlated to a decrease in doubling time from $4.7 \pm 0.3$ to $3.2 \pm 0.1$ days.

The oxygen uptake rate (OUR) of the culture was also measured throughout operation as an indicator of the culture's metabolic activity (Figure 3B). A rise in OUR correlates with cell growth, and a drop correlates with the onset of the stationary phase. Our previous studies with Nicotiana benthamiana cell culture showed that the maximum value of OUR correlated with late exponential phase, and induction at this stage can lead to higher expression of a heterologous target protein (Huang et al., 2010). Thus, each expression phase was initiated as the OUR began to level off during the growth phase. However, the OUR reached a maximum 1 day after induction in both expression phases, and this may be explained in the same way as the initial rise in biomass concentration. After this initial rise, the OUR fell as the cells starved, until a new growth phase was initiated.

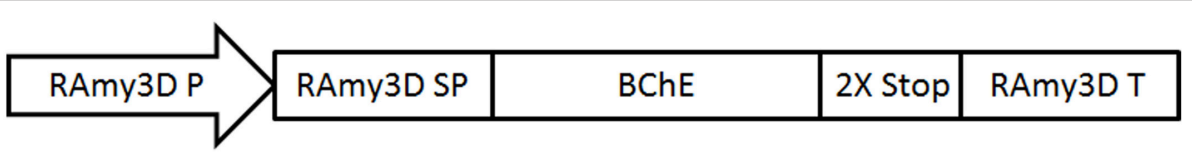

FIGURE 1 | A schematic representation of the expression vector for butyrylcholinesterase (BChE) under control of the rice alpha amylase 3D expression cassette. RAmy3D P, rice alpha-amylase 3D promoter; RAmy3D SP, rice alpha-amylase signal peptide; BChE, codon optimized synthetic human BChE gene; RAmy3D T, rice alpha-amylase terminator.

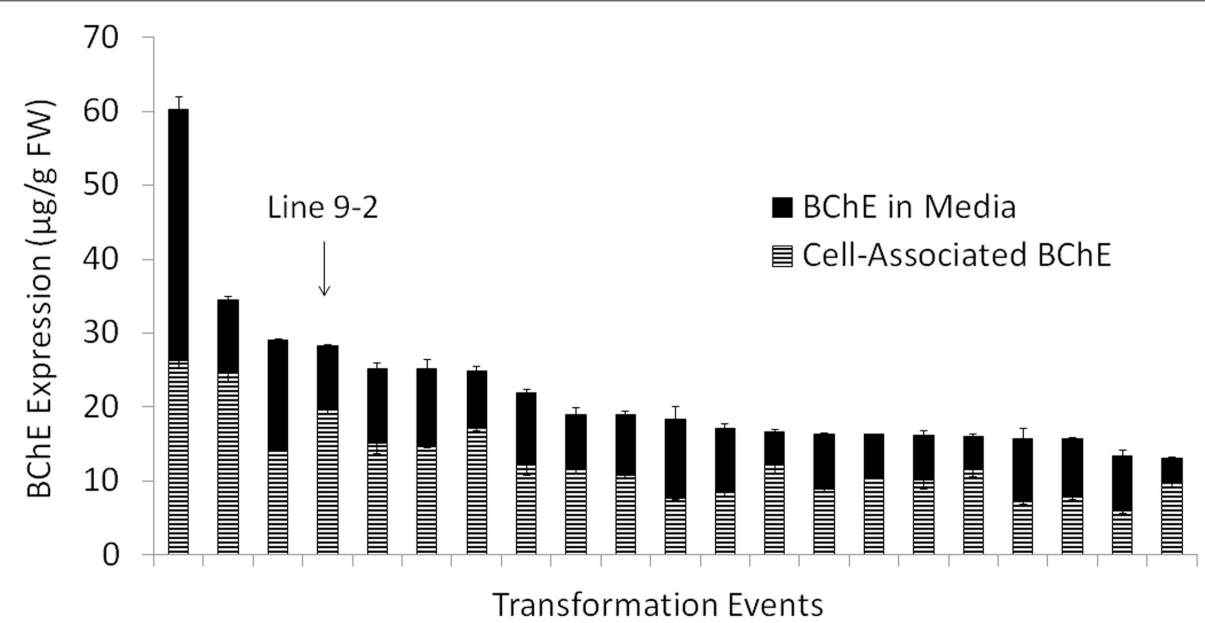

FIGURE 2 | Amount of active butyrylcholinesterase (BChE) normalized to the mass of fresh weight callus in the culture medium and associated with the biomass during the initial screening for cell line selection. Data are shown for the 20 transformation events that produced highest amount of total active BChE out of 310 total transformation events screened. The top transformation event chosen for scale up and further study (line "9-2") has been labeled. 
TABLE 1 | Biomass growth and oxygen consumption kinetic parameters for two growth phases.

\begin{tabular}{|c|c|c|c|c|}
\hline Phases & $\mu_{\max }\left(\right.$ day $\left.^{-1}\right)$ & $\tau_{D}$ (days) & Maximum OUR $\left[\mathrm{mmol} \mathrm{O}_{2} /(\mathrm{L} \cdot \mathrm{h})\right]$ & Maximum specific OUR $\left[\mathrm{mmol} \mathrm{O}_{2} /(\mathrm{g} \mathrm{DW} \cdot \mathrm{h})\right]$ \\
\hline Growth 1 & $0.15 \pm 0.01$ & $4.7 \pm 0.34$ & $0.524 \pm 0.003$ & $0.294 \pm 0.046$ \\
\hline Growth 2 & $0.22 \pm 0.01$ & $3.2 \pm 0.12$ & $1.251 \pm 0.012$ & $0.179 \pm 0.015$ \\
\hline
\end{tabular}

Key: $\mu_{\text {max }}$, maximum specific growth rate; $\tau_{D}$, doubling time; OUR, oxygen uptake rate; DW, dry weight of callus.

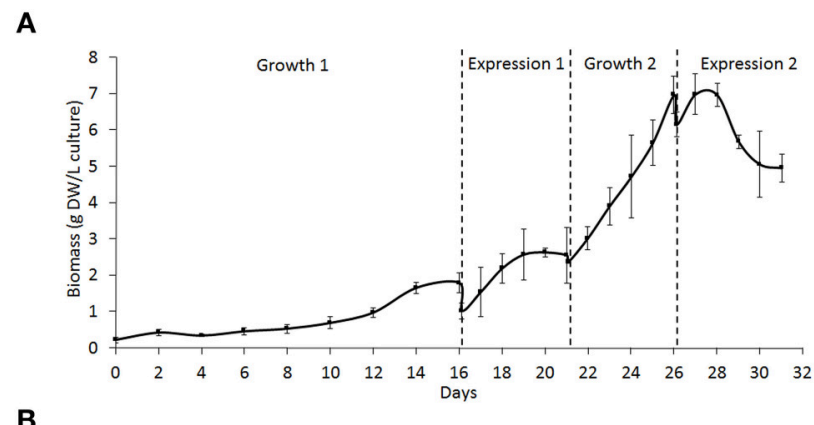

B

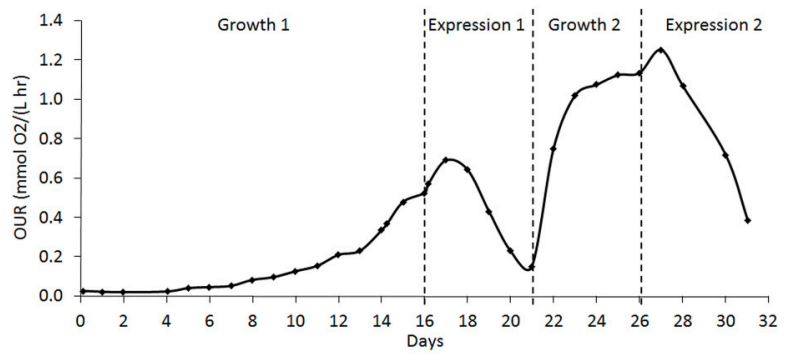

C

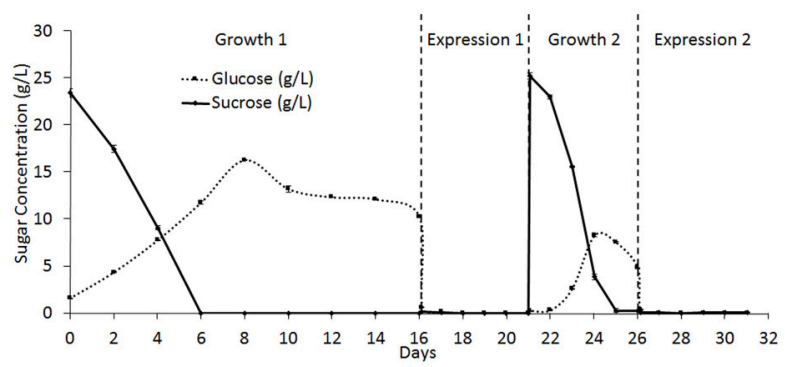

D

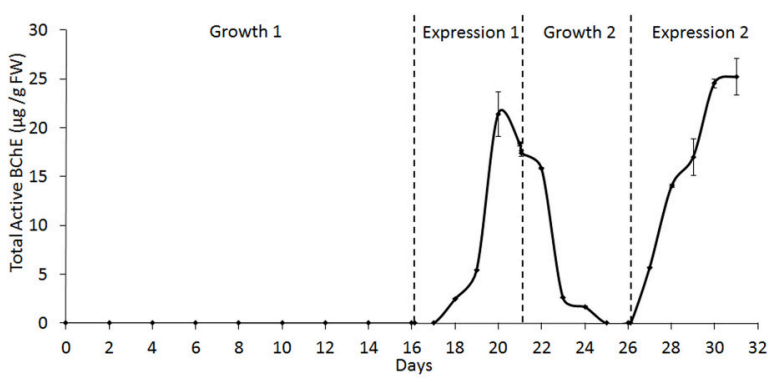

FIGURE 3 | Rice cell culture kinetics through two phases of cell growth and expression (as described in Section Materials and Methods) in a 5 $\mathbf{L}$ bioreactor. (A) Concentration of biomass in the culture in $\mathrm{g}$ of dry weight (DW) callus per $L$ of total culture. (B) Oxygen uptake rate (OUR) of the culture in $\mathrm{mmol}_{2}$ per $\mathrm{L}$ of culture per hour. (C) Concentration of glucose and sucrose found in the culture medium in $\mathrm{g} / \mathrm{L}$. (D) Total active cell-associated butyrylcholinesterase (BChE) in $\mu \mathrm{g}$, normalized to $\mathrm{g}$ of fresh weight (FW) callus.
Table 1 shows that maximum OUR increased from $0.52 \mathrm{mmol}$ $\mathrm{O}_{2} /(\mathrm{L} \cdot \mathrm{h})$ in Growth 1 to $1.25 \mathrm{mmol} \mathrm{O} /(\mathrm{L} \cdot \mathrm{h})$ in Growth 2, which is expected because this value does not account for the increase in biomass density. The maximum specific OUR actually decreases from $0.29 \mathrm{mmol} \mathrm{O}_{2} /(\mathrm{g} D W \cdot \mathrm{h})$ in Growth 1 to $0.18 \mathrm{mmol} \mathrm{O}_{2} /(\mathrm{g}$ DW.h) in Growth 2.

During growth phases, the sucrose concentration gradually decreased as it was hydrolyzed to produce equal concentrations of glucose and fructose, which can be consumed by the cells. Throughout the culture operation, the rate of hydrolysis of sucrose was faster than the rate of glucose consumption, which can be seen as a gradual decrease in sucrose concentration and increase in glucose concentration during both growth phases (Figure 3C). Both growth phases displayed the same trend, but Growth 2 showed the pattern on a shorter time scale, which is likely due to the increased biomass density. At the beginning of both expression phases, the sugar rich $(+S)$ medium is removed and replaced with sugar free medium $(-S)$, causing the concentration of both sugars to drop to and remain at $0 \mathrm{~g} / \mathrm{L}$ for the duration of the expression phase.

Active $\mathrm{BChE}$ concentration rose gradually over time during each expression phase (Figure 3D). The first expression phase (Expression 1) produced a maximum active BChE concentration of $21.4 \pm 2.3 \mu \mathrm{g} / \mathrm{g}$ FW biomass, while the second expression phase (Expression 2) produced a maximum of $25.2 \pm 1.9 \mu \mathrm{g} / \mathrm{g}$ FW biomass. Expression 1 had a lag time between induction and expression of about 2 days, and reached its maximum expression level 4 days after induction. During Growth 2, the concentration of BChE decreased gradually until it was no longer detectable. Expression 2 had a lag of $<1$ day, and reached a peak around 4 days after induction. These differences may be caused by differences in the timing of induction, the culture density, and the physiological condition of the cells. During both expression phases, the majority of $\mathrm{BChE}$ produced was associated with the cell mass. Negligible amounts of $\mathrm{BChE}$ were detected in the medium.

Table 2 summarizes the kinetic parameters of $\mathrm{BChE}$ expression. While the expression level on a per weight basis was similar for both expression phases (21.4 and $25.2 \mu \mathrm{g} / \mathrm{g} \mathrm{FW}$ ), the increased biomass density during Expression 2 lead to a much higher amount of BChE produced per liter of culture (an increase from $0.72 \mathrm{mg} / \mathrm{L}$ culture during Expression 1 to $1.64 \mathrm{mg} / \mathrm{L}$ in Expression 2). Expression 2 also had a much higher maximum volumetric productivity (based on the cycle duration including growth and expression phases) due to the absence of a long growth lag phase and increased biomass density in Growth 2 as compared to Growth 1. Finally, the ratio of BChE to TSP increased from the first to second expression phase; this may be 
due to improved adaptation during subsequent induction cycles which resulted in increased expression of BChE.

\section{Electrophoresis and Immunoblotting}

Figure 4A shows a Western blot under reducing conditions of the cell-associated BChE from samples obtained during Expression 1 and Growth 2. Equal volumes $(20 \mu \mathrm{L})$ of crude cell extract were loaded into each lane. These extracts were obtained by grinding cells in a 1:1 ratio of biomass to buffer, so the intensity of the BChE band corresponds to the concentration of BChE associated with the cells at the time each sample was taken. Under reducing conditions, a distinct band is seen around $85 \mathrm{kDa}$, which corresponds to the predicted size of a monomer of BChE. Samples taken immediately before and after induction and 2 days after induction (lanes 1-3) show no visible band, which corresponds to the low BChE activity as seen in the activity data shown in Figure 3D $(<5 \mu \mathrm{g} / \mathrm{g}$ FW $)$. The band in lane 4 corresponds to a higher value of BChE activity $(21 \mu \mathrm{g} / \mathrm{g} \mathrm{FW})$. However, while we see a decrease in BChE activity from day 20 to 21 (a drop from 21 to $18 \mu \mathrm{g} / \mathrm{g} \mathrm{FW}$ ), there is an increase in the intensity of the BChE band seen in the Western blot in lanes 5 and 6 (which correspond to samples taken immediately before and after initiation of Growth 2 on day 21). This may indicate that a portion of the BChE detected in the Western blot is inactive.

To determine the oligomerization status of the rice cell culture-produced $\mathrm{BChE}$, we performed Western blot analysis under native conditions on a crude cell extract from Expression 1 (Figure 4B). Lane 2 contains $200 \mathrm{ng}$ of purified equine serum $\mathrm{BChE}$ (as human BChE has been commercially unavailable for over a year), which is about $440 \mathrm{kDa}$ in its tetrameric form. The cell extract shows two bands, one smaller and one larger than the equine control. The smaller product is near the expected size of tetrameric $\mathrm{BChE}(340 \mathrm{kDa})$, while the other may be an aggregation product.

\section{DISCUSSION}

The size and complexity of BChE has been a major impediment in its production in any recombinant expression host. Despite high expression levels (up to $5 \mathrm{~g} / \mathrm{L}$ of milk), transgenic goats are able to produce primarily dimeric $\mathrm{BChE}$, which exhibits a reduced circulatory half-life ( $\sim 2 \mathrm{~min}$ ) in vivo (Huang et al., 2007). Many attempts have been made to solve this problem, including PEGylation (Sun et al., 2013) or sialylation (Ilyushin et al., 2013) to increase this half-life, and addition of a prolinerich peptide to encourage tetramerization (Larson et al., 2014; Terekhov et al., 2015). Recent work by Schneider et al. also reports difficulty in secretion of $\mathrm{BChE}$ oligomers produced by transient expression in $N$. benthamiana, despite the molecule's ability to tetramerize in a crude cell extract (Schneider et al., 2014b). Recombinant tetrameric BChE has been produced in other cell culture types and reached up to $70 \mathrm{mg} / \mathrm{L}$ of culture (Terekhov et al., 2015), but these cultures have been limited by a comparatively high cost of culture operation and increased potential for contamination from human pathogens.
Previous work by our group has demonstrated successful semicontinuous production of a fully active alpha-1-antitrypsin under control of the RAmy3D expression system in a transgenic rice cell culture (Huang et al., 2001; Trexler et al., 2002, 2005). In the current study, we successfully produced an intact and active form of BChE, a larger and more complex glycoprotein therapeutic. A maximum of $1.6 \mathrm{mg} / \mathrm{L}$ of culture was produced during the second expression phase in a relatively non-optimized system. We expect that further refinements of the operational strategy will increase expression levels to those of other cell culture systems. For example, Park et al. have demonstrated a fedbatch operational strategy, in which the culture is supplemented with a concentrated solution of amino acids prior to sugar depletion, that can enhanced product yields up to 1.8 -fold compared to induction via medium exchange (Park et al., 2010).

One major advantage of our system is that we can produce predominantly active and fully assembled tetrameric BChE. This underscores the importance of this system as a safe and cost-effective method for production of human biotherapeutics. In addition to growing on an inexpensive culture medium, long-term semicontinuous operation of the culture reduces the need for long seed trains and minimizes turn-around time, clean-in-place and steam-in-place operations, chemicals, and energy. Furthermore, the regulatory pathway for plant-based recombinant biologics for human therapeutic use has now been established with the production and regulatory approval of taliglucerase alfa (Elelyso ${ }^{\mathrm{TM}}$ ) produced in carrot cell suspension in batch culture for the treatment of Gaucher's disease (Maxmen, 2012).

After the initial inoculation, the culture experienced a long lag phase in cell growth. The process of sieving the callus through a stainless steel mesh to obtain small cell aggregates may be physically stressful for the cells, thus requiring a longer initial growth period to acclimatize. This may be part of the reason that Growth 2, which involved the same biomass but no sieving immediately before the growth phase, did not exhibit the same lag phase and reached a maximum OUR value within 5 days. During expression phases, the culture reached a maximum expression level of BChE around day 4 after induction. Thus, after an initial acclimatization period, the culture can operated by alternating between 5-day growth phases and 4-day expression phases to maximize BChE productivity over longer periods.

The negligible release of $\mathrm{BChE}$ in the culture medium during bioreactor operation (in comparison to the screening stage, where a significant portion of $\mathrm{BChE}$ was secreted into the medium) may be due to the size of both the protein $(340 \mathrm{kDa})$ and the larger size of the cell aggregates in comparison to the screening stage. For BChE to be released into the medium, BChE must not only be secreted from the cell, but must also pass through the cell wall and diffuse through the cell aggregate. The tetrameric form of $\mathrm{BChE}$ is about $50-60 \mathrm{~nm}$ (Lockridge et al., 2011), while the average pore size of the plant cell wall is $35-50 \mathrm{~nm}$ (Carpita et al., 1979) in differentiated plant cells. If tetrameric $\mathrm{BChE}$ is produced inside the cell and secreted in its fully assembled form, the protein may be trapped inside 
the cell wall or within the aggregate and only released during homogenization. Even if the tetramer is assembled after secretion, the monomers or the fully assembled tetramer still must diffuse through the cell aggregate to reach the culture medium. Because early screening experiments were done at small scale, the aggregates could be easily broken apart before expression level studies. Here, as shown in Figure 2, we saw roughly 30-60\% of the total BChE secreted into the medium for most cell lines. However, with each subsequent screening, we saw a reduction in the proportion of $\mathrm{BChE}$ secreted into the medium. This can be explained by the fact that each subsequent screening was performed at an increasingly larger scale, which made it more difficult to break apart large aggregates. These larger aggregates provide a more challenging route through which secreted $\mathrm{BChE}$ must diffuse into the culture medium, and can explain why the proportion of secreted $\mathrm{BChE}$ dropped to nearly zero in later cultures.

The issue of low secretion levels may be addressed by decreasing the size of cell aggregates through alteration of medium composition or operating parameters (particularly, agitation, aeration rates, and length of growth and expression phases). However, it is also possible that oligomeric $\mathrm{BChE}$ is not able to correctly pass through the secretory pathway completely, as has been seen in other plant systems (Schneider et al., 2014b), and early screenings detected a small amount of monomeric BChE that was able to secrete effectively. To address this possibility, we are developing an alternate semicontinuous operation format similar to that described by Huang et al. (2010), in which a portion of the biomass is harvested after an expression phase, while the remaining biomass remains in the reactor as inoculum for the next growth phase.

\section{CONCLUSIONS AND FUTURE PROSPECTS}

Active recombinant $\mathrm{BChE}$ was produced in a transgenic rice cell suspension culture using an inducible gene expression system. Two complete phases of cell growth and BChE expression were performed, and the cells were able to express milligram quantities of active BChE during both expression phases and successfully regrow during a growth phase. Theoretically, these cultures could be operated indefinitely, and our goal is to evaluate the behavior and productivity of the culture during long-term (several months) operation, and if necessary by keeping a portion of the cells as inoculum to the medium in subsequent cycles. Further development of the culture and operation modes will aim to increase the amount of $\mathrm{BChE}$ produced and secreted into the culture medium, and to perform a more comprehensive

TABLE 2 | Maximum values of butyrylcholinesterase (BChE) expression kinetic parameters for two expression phases.

\begin{tabular}{lcccc}
\hline Phases & BChE expression $(\boldsymbol{\mu} \mathbf{g} / \mathbf{g ~ F W})$ & BChE expression $(\mathbf{m g} / \mathbf{L}$ culture) & Volumetric productivity $(\boldsymbol{\mu} \mathbf{g} / \mathbf{L} \cdot$ day) & Purity $(\%$ BChE/TSP) \\
\hline Expression 1 & $21.4 \pm 2.3$ & $0.72 \pm 0.16$ & $35.8 \pm 7.7$ & $0.27 \pm 0.02$ \\
Expression 2 & $25.2 \pm 1.9$ & $1.64 \pm 0.15$ & $183.8 \pm 17.3$ & $0.55 \pm 0.03$ \\
\hline
\end{tabular}

Key: FW, fresh weight of callus; TSP, total soluble protein.
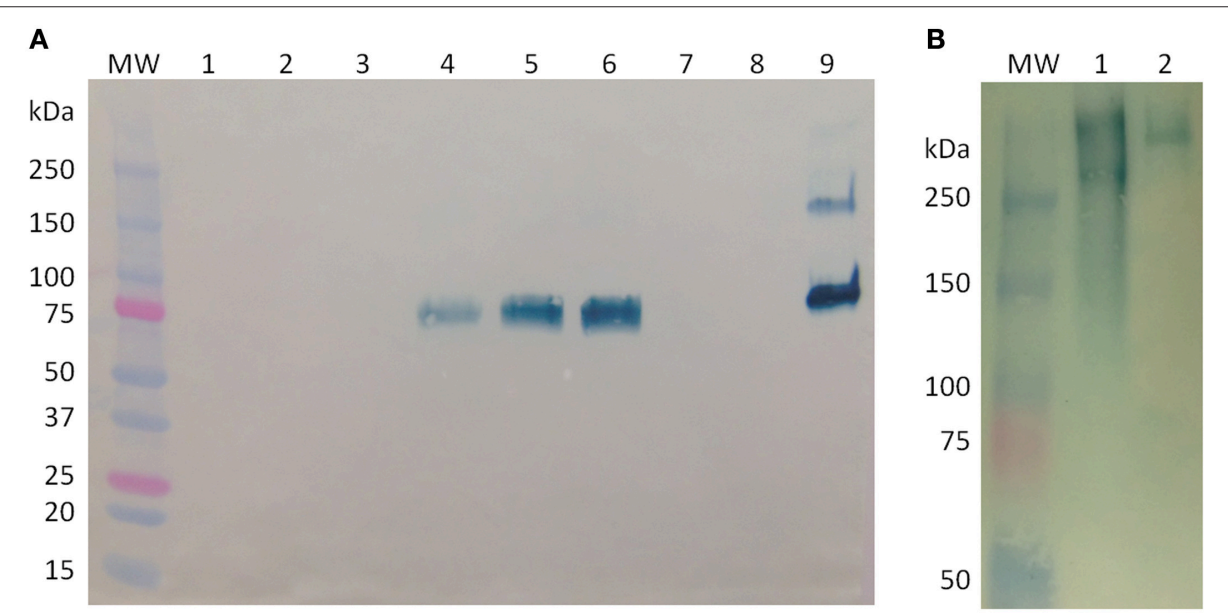

FIGURE 4 | Western blot analysis of butyrylcholinesterase (BChE) produced in rice cell culture. (A) Western blot under reducing conditions of cell-associated samples from before and after medium exchanges. Each lane contains $20 \mu \mathrm{L}$ of crude cell extract. Lane MW: molecular weight ladder; lane 1, day 16 , immediately before start of Expression phase 1; lane 2, day 16, immediately after start of Expression Phase 1; lane 3, day 18; lane 4, day 20; lane 5, day 21, immediately before start of Growth phase 2; lane 6, day 21, immediately after start of Growth phase 2; lane 7, day 23; lane 8, day 25; lane 9, control, 900 ng purified equine BChE. (B) Western blot under native conditions of BChE. Lane MW: molecular weight ladder; lane 1: $52 \mathrm{U}(\sim 200 \mathrm{ng})$ active BChE from an intracellular sample from day 3 of Expression phase 1; lane 2: control, 200 ng purified equine BChE. 
characterization of BChE, including determination of the serum half-life and the glycosylation profile of the product.

\section{AUTHOR CONTRIBUTIONS}

JC, led and designed experiments and wrote and edited the manuscript. $\mathrm{BH}$, led and designed experiments. KK, conceptualized and assisted with performing and designing experiments. ZK, assisted with experiments. LW, performed experiments. BR, conceptualized. AN, conceptualized. RR, conceptualized and edited the manuscript. KM, conceptualized,

\section{REFERENCES}

Bradford, M. M. (1976). A rapid and sensitive method for the quantitation of microgram quantities of protein utilizing the principle of protein-dye binding. Anal. Biochem. 72, 248-254. doi: 10.1016/0003-2697(76)90527-3

Brazzolotto, X., Wandhammer, M., Ronco, C., Trovaslet, M., Jean, L., Lockridge, O., et al. (2012). Human butyrylcholinesterase produced in insect cells: huprine-based affinity purification and crystal structure. FEBS J. 279, 2905-2916. doi: 10.1111/j.1742-4658.2012.08672.x

Carpita, N., Sabularse, D., Montezinos, D., and Delmer, D. P. (1979). Determination of the pore size of cell walls of living plant cells. Science 205, 1144-1147. doi: 10.1126/science.205.4411.1144

Chih-Ching, C., Ching-Chu, W., Ching-San, S., Chen, H., Kwang-Chu, Y., ChihYin, C., et al. (1975). Establishment of an efficient medium for anther culture of rice through comparative experiments on the nitrogen sources. Sci. China Math. 18, 659-668.

DARPA (2012). Broad Agency Annoucement 12-31: Butyrylcholinesterase Expression in Plants. Arlington, TX: D.S.O. Defense Advanced Research Projects Agency (DARPA).

Duysen, E. G., Bartels, C. F., and Lockridge, O. (2002). Wild-type and A328W mutant human butyrylcholinesterase tetramers expressed in chinese hamster ovary cells have a 16-hour half-life in the circulation and protect mice from cocaine toxicity. J. Pharmacol. Exp. Ther. 302, 751-758. doi: 10.1124/jpet.102.033746

Ellman, G. L., Courtney, K. D., Andres, V. Jr., and Featherstone, R. M. (1961). A new and rapid colorimetric determination of acetylcholinesterase activity. Biochem. Pharmacol. 7, 88-95. doi: 10.1016/0006-2952(61)90145-9

Gamborg, O. L., Miller, R. A., and Ojima, K. (1968). Nutrient requirements of suspension cultures of soybean root cells. Exp. Cell Res. 50, 151-158. doi: 10.1016/0014-4827(68)90403-5

Geyer, B. C., Kannan, L., Cherni, I., Woods, R. R., Soreq, H., and Mor, T. S. (2010). Transgenic plants as a source for the bioscavenging enzyme, human butyrylcholinesterase. Plant Biotechnol. J. 8, 873-886. doi: 10.1111/j.14677652.2010.00515.x

Huang, J., Wu, L., Yalda, D., Adkins, Y., Kelleher, S., Crane, M., et al. (2002). Expression of functional recombinant human lysozyme in transgenic rice cell culture. Transgenic Res. 11, 229-239. doi: 10.1023/A:1015663706259

Huang, J. M., Sutliff, T. D., Wu, L. Y., Nandi, S., Benge, K., Terashima, M., et al. (2001). Expression and purification of functional human alpha1-antitrypsin from cultured plant cells. Biotechnol. Prog. 17, 126-133. doi: $10.1021 / \mathrm{bp} 0001516$

Huang, K., and McDonald, K. A. (2012). Bioreactor systems for in vitro production of foreign proteins using plant cell cultures. Biotechnol. Adv. 30, 398-409. doi: 10.1016/j.biotechadv.2011.07.016

Huang, T. K., Plesha, M. A., and McDonald, K. A. (2010). Semicontinuous bioreactor production of a recombinant human therapeutic protein using a chemically inducible viral amplicon expression system in transgenic plant cell suspension cultures. Biotechnol. Bioeng. 106, 408-421. doi: 10.1002/bit.22713

Huang, Y. J., Huang, Y., Baldassarre, H., Wang, B., Lazaris, A., Leduc, M., et al. (2007). Recombinant human butyrylcholinesterase from milk designed experiments, and edited the manuscript. SN, conceptualized, designed experiments, and edited the manuscript.

\section{ACKNOWLEDGMENTS}

Funding for this project was provided by Leidos, Inc. (Frederick, $\mathrm{MD})$ and by the National Institutes of Health, National Institute of General Medical Sciences (NIGMS-NIH) (Grant Number T32GM008799). Its contents are solely the responsibility of the authors and do not necessarily represent the official views of the NIGMS or NIH. of transgenic animals to protect against organophosphate poisoning. Proc. Natl. Acad. Sci. U.S.A. 104, 13603-13608. doi: 10.1073/pnas.07027 56104

Ilyushin, D. G., Smirnov, I. V., Belogurov, A. A. Jr., Dyachenko, I. A., Zharmukhamedova, T., Novozhilova, T. I., et al. (2013). Chemical polysialylation of human recombinant butyrylcholinesterase delivers a long-acting bioscavenger for nerve agents in vivo. Proc. Natl. Acad. Sci. U.S.A. 110, 1243-1248. doi: 10.1073/pnas.1211118110

Larson, M. A., Lockridge, O., and Hinrichs, S. H. (2014). Polyproline promotes tetramerization of recombinant human butyrylcholinesterase. Biochem. J. 462, 329-335. doi: 10.1042/BJ20140421

Lenz, D. E., Maxwell, D. M., Koplovitz, I., Clark, C. R., Capacio, B. R., Cerasoli, D. M., et al. (2005). Protection against soman or VX poisoning by human butyrylcholinesterase in guinea pigs and cynomolgus monkeys. Chem. Biol. Interact. 157-158, 205-210. doi: 10.1016/j.cbi.2005. 10.025

Lockridge, O. (2015). Review of human butyrylcholinesterase structure, function, genetic variants, history of use in the clinic, and potential therapeutic uses. Pharmacol. Ther. 148, 34-46. doi: 10.1016/j.pharmthera.2014. 11.011

Lockridge, O., Duysen, E. G., and Masson, P. (2011). "Butyrylcholinesterase: overview, structure, and function, anticholinesterase pesticides," in Anticholinesterase Pesticides: Metabolism, Neurotoxicity, and Epidemiology, eds T. Satoh and R. C. Gupta (Hoboken, NJ: John Wiley \& Sons, Inc.), 25-41.

Maxmen, A. (2012). Drug-making plant blooms. Nature 485, 160. doi $10.1038 / 485160$ a

Park, C.-I., Lee, S.-J., Kang, S.-H., Jung, H.-S., Kim, D.-I., and Lim, S.-M. (2010). Fed-batch cultivation of transgenic rice cells for the production of hCTLA4Ig using concentrated amino acids. Process Biochem. 45, 67-74. doi: 10.1016/j.procbio.2009.08.004

Pawar, B., Kale, P., Bahurupe, J., Jadhav, A., Kale, A., and Pawar, S. (2015). Proline and glutamine improve in vitro callus induction and subsequent shooting in rice. Rice Sci. 22, 283-289. doi: 10.1016/j.rsci.2015. 11.001

Raven, N., Rasche, S., Kuehn, C., Anderlei, T., Klockner, W., Schuster, F., et al. (2015). Scaled-up manufacturing of recombinant antibodies produced by plant cells in a 200-l orbitally-shaken disposable bioreactor. Biotechnol. Bioeng. 112, 308-321. doi: 10.1002/bit.25352

Schneider, J. D., Castilho, A., Neumann, L., Altmann, F., Loos, A., Kannan, L., et al. (2014a). Expression of human butyrylcholinesterase with an engineered glycosylation profile resembling the plasma-derived orthologue. Biotechnol. J. 9, 501-510. doi: 10.1002/biot.201300229

Schneider, J. D., Marillonnet, S., Castilho, A., Gruber, C., Werner, S., Mach, L., et al. (2014b). Oligomerization status influences subcellular deposition and glycosylation of recombinant butyrylcholinesterase in Nicotiana benthamiana. Plant Biotechnol. J. 12, 832-839. doi: 10.1111/pbi.12184

Sun, W., Luo, C., Tipparaju, P., Doctor, B. P., and Saxena, A. (2013). Effect of polyethylene glycol conjugation on the circulatory stability of plasma-derived human butyrylcholinesterase in mice. Chem. Biol. Interact. 203, 172-176. doi: 10.1016/j.cbi.2012.11.021 
Terekhov, S., Smirnov, I., Bobik, T., Shamborant, O., Zenkova, M., Chernolovskaya, E., et al. (2015). A novel expression cassette delivers efficient production of exclusively tetrameric human butyrylcholinesterase with improved pharmacokinetics for protection against organophosphate poisoning. Biochimie 118, 51-59. doi: 10.1016/j.biochi.2015. 07.028

Trexler, M. M., McDonald, K. A., and Jackman, A. P. (2002). Bioreactor production of human $\alpha 1$-antitrypsin using metabolically regulated plant cell cultures. Biotechnol. Prog. 18, 501-508. doi: 10.1021/bp02 0299k

Trexler, M. M., McDonald, K. A., and Jackman, A. P. (2005). A cyclical semicontinuous process for production of human al-antitrypsin using metabolically induced plant cell suspension cultures. Biotechnol. Prog. 21, 321-328. doi: 10.1021/bp0498692
Conflict of Interest Statement: The authors declare that the research was conducted in the absence of any commercial or financial relationships that could be construed as a potential conflict of interest.

$\mathrm{KM}$ is a co-founder of Inserogen, Inc., a plant-based biotechnology company with a focus on the development of orphan drugs for replacement therapy.

Copyright $\odot 2016$ Corbin, Hashimoto, Karuppanan, Kyser, Wu, Roberts, Noe, Rodriguez, McDonald and Nandi. This is an open-access article distributed under the terms of the Creative Commons Attribution License (CC BY). The use, distribution or reproduction in other forums is permitted, provided the original author(s) or licensor are credited and that the original publication in this journal is cited, in accordance with accepted academic practice. No use, distribution or reproduction is permitted which does not comply with these terms. 